\title{
The Role Of School Life Expectancy And Urbanization On Adult Literacy Rates In Sub-Saharan Africa
}

Amon Okpala, Fayetteville State University, USA

Comfort Okpala, North Carolina A\&T State University, USA

\begin{abstract}
It is important to examine the role of urbanization, government, and school life expectancy (the years of schooling a child is expected to have) on adult literacy because literacy contributes to economic success. Using cross-sectional data on 46 Sub-Saharan African countries, this study examines 1) the impact of school life expectancy on adult literacy, 2) the influence of urban population on adult literacy, and 3) the effectiveness of government educational expenditure on adult literacy. OLS regression analysis showed that the percentage of the population residing in urban centers and the school life expectancy were positively significant at the 5 percent level. Government expenditure, as a percentage of GDP, was positively significant at the 1 percent level.
\end{abstract}

Keywords: School Life Expectancy; Urbanization; Adult Literacy

\section{INTRODUCTION}

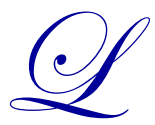

iteracy has always been a global phenomenon, especially in Sub-Saharan Africa. Differences in the standard of living among nations are mainly due to varying degrees of labor productivity. Some nations are poor mainly due to low labor productivity. A very important source of labor productivity is human capital - the skill, experience, and education of workers. When knowledge is lacking, it leads to inefficient use of other resources. Education makes the worker more aware of the latest technology, to be more receptive to the new approaches and methods, and, finally, to be more productive.

Although literacy has improved somewhat in Sub-Saharan Africa, large numbers of people residing in rural regions still cannot read. Meier and Rauch (2005) have shown that large disparities in educational opportunities persist both in enrollment numbers, which capture educational flows, and in average years of schooling, which are taken to represent the stock of education among the public. According to Okpala \& Okpala (2009), this disparity is more pronounced among rural residents because of the lack of educational opportunities. A lasting observation about literacy in any country is that it transforms people from passive into active citizens. Literacy also helps in the migration of labor. An educated worker can be more aware of employment opportunities elsewhere and can migrate to improve their standard of living.

The economic impact of literacy to any society can be observed from both the micro and the macro levels (Psacharopoulos, 1991). Efforts to improve literacy rates are regarded as investments that contribute tremendously to human capital. This contribution could be for the individual or for the country at large. In a simplified form, the rate of return, $\mathrm{R}$, on an investment that improves the literacy rate can be specified as:

$\mathrm{R}=\left(\mathrm{Y}_{\text {ed }}-\mathrm{Y}_{\mathrm{ue}}\right) / \mathrm{N}\left(\mathrm{Y}_{\mathrm{ue}}+\mathrm{C}_{\mathrm{t}}\right)$

where $Y_{e d}$ and $Y_{u e}$ refer, respectively, to the mean income of workers who are educated and uneducated. $N$ is the number of years of schooling required to become literate. $C_{t}$ is the annual cost of schooling. Returns on investment in educational activities are much greater in developing nations than those observed in advanced nations. This is 
especially noteworthy if extended family systems exist, as they do in most of Sub-Saharan Africa. If family members attend schools, seek urban employment, or start a new retail business, the larger family unit pools their financial support to help in contributing to economic development. When a family member acquires more wealth, he helps less fortunate members of the extended family.

Because literacy contributes tremendously to the overall economy, it is important to re-examine not only the role that urban population and government education expenditures have on adult literacy, but also the impact of school life expectancy (the number of years of schooling that a person is expected to have) on literacy. This study is motivated by the overwhelming importance of the implications that literacy rates have on the economy. The study attempts to answer the following research questions:

1. What is the role of school life expectancy on adult literacy?

2. How will the degree of urbanization of the population impact adult literacy?

3. How effective is government educational expenditure as a percentage of GDP in influencing adult literacy rates?

\section{Theoretical Perspectives}

This study is grounded in post-positivist perspective where causes determine the effects and outcomes (Creswell, 2009). In this study, the role of school life expectancy, the role of urbanization, and the level of educational expenditures by Sub-Saharan African countries is expected to determine the adult literacy outcomes. This study also relies on research constructs in adult literacy. Several studies on adult literacy have emphasized the implications of adult literacy on labor force participation as well as on the sustainability of economic growth and development (Comings, Sum, \& Uvin, 2000; Kerckhoff, Raudenbush, \& Glennie, 2001).

\section{METHODOLOGY AND DATA}

This study uses cross-sectional data on 46 Sub-Saharan African countries. The data were obtained from the most current (2010-2012) CIA World Facts Book. The study uses least squared (OLS) regression analysis to answer the research questions and cross-tabulation analysis to highlight some unique and major characteristics of the data.

\section{Dependent Variable}

\section{Adult Literacy (LR)}

This entry includes a definition of literacy and Census Bureau percentages for the total population, males, and females. There are no universal definitions and standards of literacy. All rates are based on the most common definition - the ability to read and write at a specified age. Information on literacy, while not a perfect measure of educational results, is the most valid and easily available for international comparisons. Literacy rates can help or impede the economic development of a country, especially in today's rapidly changing world.

\section{Explanatory Variables}

\section{School Life Expectancy (SLE)}

This is the total number of years of schooling (primary to tertiary) that a child can expect to receive, assuming that the probability of his or her being enrolled in school at any particular future age is equal to the current enrollment ratio at that age. One must be cautious when utilizing this indicator, especially in international comparisons. A year or grade completed in one country is not necessarily the same in terms of educational content or quality as a year or grade completed in another country. SLE represents the expected number of years of schooling that a child will complete, including years spent repeating one or more grades. It is expected that SLE will have a positive impact on adult literacy rates. 


\section{Urbanization (URB)}

This entry provides a measure of the degree of urbanization of a population. It describes the percentage of the country's total population living in urban areas. An urban agglomeration is defined as comprising the city or town proper and also the suburban fringe or thickly settled territory lying outside of, but adjacent to, the boundaries of the city. URB is expected to have a positive impact on adult literacy.

\section{Education Expenditures (EE)}

This entry provides the public expenditure on education as a percent of GDP. This includes public spending on public schools plus subsidies to private education at primary, secondary, and tertiary levels. EE is expected to influence adult literacy positively.

\section{RESULTS}

Table 1 illustrates the descriptive statistics of all the variables used in this study. According to the data illustrated in the 2010-2012 CIA World Facts Book used for this study, the minimum school life expectancy of 3 is observed in Somalia, while the maximum of 13 occurred in South Africa. The literacy rate for South Africa was 86.4 percent, while Somalia had 37.3 percent. Further examination shows that the minimum adult literacy of 21.0 percent occurred in Burkina Faso, while the maximum adult literacy rate of 92.0 percent was observed in Equatorial Guinea. It is interesting to note that only about 26 percent of people from Burkina Faso reside in urban centers, according to the CIA World Facts Book. Government expenditures on education were 0.6 percent of GDP in South Sudan and 13 percent of GDP in Lesotho, with respective literacy rates of 27 percent and 89.6 percent.

Table 1: Descriptive Statistics

\begin{tabular}{|l|c|c|c|c|}
\hline \multicolumn{1}{|c|}{ Variables } & Minimum (Countries) & Maximum (Countries) & Mean & Std. Dev. \\
\hline LR & 21 (Burkina Faso) & 92.9 (Equatorial Guinea) & 63.39 & 20.01 \\
\hline URB & 11 & 86 & 43.11 & 16.20 \\
\hline SLE & 3 (Somalia) & 13 (South Africa) & 8.96 & 2.45 \\
\hline EE & 0.6 (South Sudan) & 13 (Lesotho) & 5.02 & 2.29 \\
\hline
\end{tabular}

Note: LR - Adult Literacy Rate; URB - Degree of Urbanization; SLE - School Life Expectancy; EE - Education Expenditure

OLS regression was performed to analyze the effects and significance of each of the explanatory variables on adult literacy rates among Sub-Saharan Africa countries. The regression model is:

$L R i=\beta_{1}+\beta_{2} \mathrm{SLE}_{\mathrm{i}}+\beta_{3} \mathrm{URB}_{\mathrm{i}}+\beta_{4} \mathrm{EE}_{\mathrm{i}}+\mu_{\mathrm{i}}$

where $\beta$ 's represent coefficient estimates and $\mu_{\mathrm{i}}$ represents the stochastic term. The regression results (see Table 2) indicate that school life expectancy is positively related to adult literacy at a statistically significant level of 95 percent. This implies, as expected, that the greater the number of years a child is exposed to learning activities, the more literate he will be as an adult. Sub-Saharan African nations that allow their children to spend more years in school will end up later with better and more literate functioning adults. This further implies that investing in education in the early years of life does pay dividends later. The regression results also indicate that the percentage of the population that resides in urban areas is statistically significant in explaining changes in adult literacy at the 95 percent level. The greater the percentage of the population that resides in urban areas, the higher the adult literacy rates, which is consistent with previous research (Okpala \& Okpala, 2009).

The regression results also illustrate that government expenditures in learning activities contribute tremendously in the eradication of illiteracy. It was found that government expenditures on education positively influenced literacy at a 99 percent significance level. In another study on youth literacy (Okpala \& Okpala, 2006), the result was different; public expenditures were statistically insignificant in explaining changes in youth literacy. The reasons given for that result were poor governance, corruption, and lack of adequate financial contribution on the part of sub-Saharan African governments. Overall, government education expenditure plays an important role in helping improve literacy rates in Sub-Saharan Africa. 
Table 2: OLS Estimates of School Life Expectancy (SLE), Degree of Urbanization (URB), and Education Expenditure (EE) on Adult Literacy

\begin{tabular}{|l|c|}
\hline \multicolumn{1}{|c|}{ Explanatory Variables } & Coefficient Estimates \\
\hline Constant & 11.484 \\
\hline \multirow{2}{*}{ SLE } & 2.459 \\
& $(2.424)^{* * *}$ \\
\hline \multirow{2}{*}{ URB } & 0.369 \\
& $(2.443)^{* *}$ \\
\hline \multirow{2}{*}{ EE } & 2.782 \\
& $(2.582)^{*}$ \\
\hline R-Square & 0.494 \\
\hline Adjusted R-Square & 0.458 \\
\hline
\end{tabular}

Note: T-statistics are given in parenthesis. *Statistically significant at the $1 \%$ level. **Statistically significant at the $5 \%$ level.

\section{CONCLUSION}

The ability to read is associated with a positive outcome. Investment in education contributes to the overall economy through the improvement in literacy and in human capital, more generally. Lind (1997) has argued that the individual empowerment effects associated with literacy are quite powerful, especially when dealing with maledominated African society. Using cross-sectional data of 46 sub-Saharan African countries, this study has examined 1) the impact of school life expectancy on adult literacy, 2) the influence of urban population on adult literacy, and 3 ) the effectiveness of government educational expenditure on adult literacy. Using OLS regression analysis, the percentage of the population residing in urban centers and the school life expectancy were found to be positive and significant at the 95 percent level, and government expenditure as a percentage of GDP was positive and significant at the 99 percent level.

\section{IMPLICATIONS}

Government plays a vital role in improving adult literacy rates in Sub-Saharan Africa because of the positive relationship between the percent of GDP spent on educational activities and literacy. Policymakers should increase financial support to educational activities.

\section{AUTHOR INFORMATION}

Amon Okpala is a Professor of Economics. He has published several articles and reviewed several books that have appeared in the following journals: International Journal of Commerce \& Management, Journal of Education for Business, Journal of Educational Research, Atlantic Economic Journal, Journal of Applied Business Research, Journal of Developing Society, Journal of Developing Areas, The Review of Black Political Economy, Journal of Instructional Psychology, and The Journal of Modern African Studies. His research interests include the economics of population dynamics, economics of education, financial markets, and foreign exchange markets. E-mail: aokpala@uncfsu.edu (Corresponding author)

Comfort Okpala is a Professor of Leadership Studies at North Carolina A\&T State University, Greensboro, North Carolina. Dr. Comfort Okpala has published several articles that have appeared in the following journals: Journal of Education Finance, Journal of Education for Business, Journal of Educational Research, Journal of Instructional Psychology, Journal of Applied Business Studies, Journal of Negro Education, Education, Urban Education, and Journal of Research in Childhood Education. Her research interests focus on educational assessments, school finance policy issues, educational accountability, school choice, school resources allocation, and African studies. E-mail: cookpala@ncat.edu

\section{REFERENCES}

1. Comings, J., Sum, A., \& Uvin, J. (2000). New skills for a new economy: Adult education's key role in sustaining economic growth and expanding opportunities. Boston, MA: Mass Inc. 
2. Creswell, J. (2009). Research design: Qualitative, quantitative and mixed methods approaches ( $2^{\text {nd }}$ ed.). Thousand Oaks, CA: Sage Publications.

3. Kerckhoff, C. Raudenbush, S., \& Glennie, E. (2001). Education, cognitive skills, and labor force outcomes. Sociology of Education, 74, 1.24.

4. Lind, A. (1997). Adult literacy in the Third World - A review of trends a decade later. NORRAGNEWS, 21, 31-35.

5. Meier, G., \& Rauch, J. (2005). Three views of the contribution of education to economic growth. In Meier \& Rauch (ed.), Leading issues in economic development (pp. 187-188). Oxford University Press, Oxford.

6. Okpala, A., \& Okpala, C. (2009). Economics \& religious implications on adult literacy in sub-Saharan Africa. The Journal of Applied Business Research, 25(1), 83-90.

7. Okpala, A., \& Okpala, C. (2006). The effects of public expenditure and parental education on youth literacy in sub-Saharan Africa. Journal of Third World Studies, 203-212.

8. Psacharopoulos (1991). The economic impact of education: Lessons for policy makers (pp. 8-15). San Francisco: ICS Press. 
NOTES 